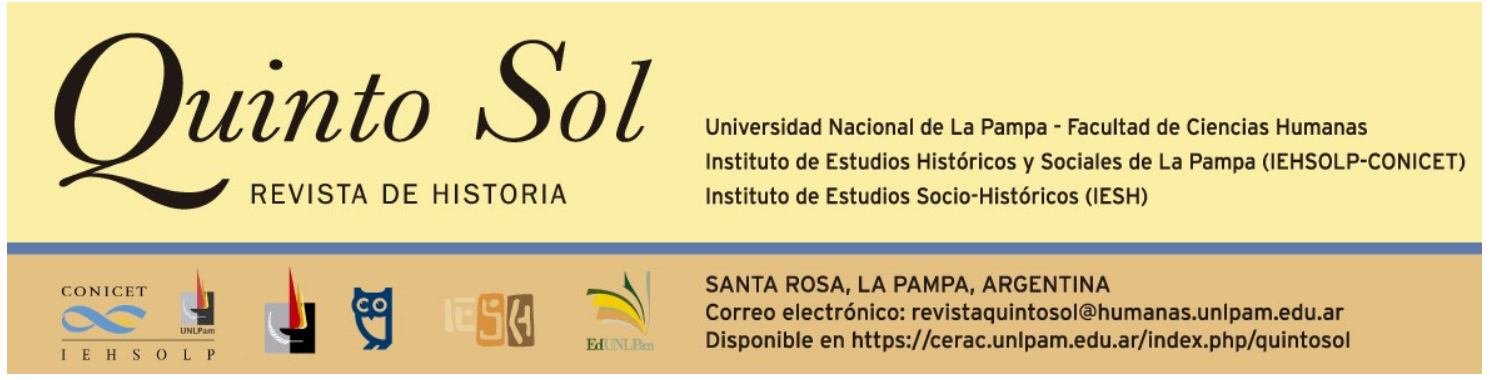

Quinto Sol, vol. 24, n² 2, mayo-agosto 2020 ISSN 1851-2879, pp. 1-4

DOI: http://dx.doi.org/10.19137/qs.v24i2.4271

Esta obra se publica bajo licencia Creative Commons 4.0 Internacional. (Atribución-No ComercialCompartir lgual)

\title{
Fabio Kolar y Ulrich Mücke (Eds.) El pensamiento conservador y derechista en América Latina, España Portugal, siglos XIX y XX. Madrid: Iberoamericana- Vervuert, 2019, 362 páginas.
}

\author{
Olga Echeverría \\ Consejo Nacional de Investigaciones Científicas y Técnicas \\ Universidad Nacional del Centro de la Provincia de Buenos Aires. Instituto de Estudios Históricos Sociales \\ "Profesor Juan Carlos Grosso". Instituto de Geografía, Historia y Ciencias Sociales \\ Argentina \\ Correo electrónico: Olgaecheverria23@gmail.com
}

El pensamiento conservador y derechista en América Latina, España y Portugal, siglos $X I X$ y $X X$, el libro compilado por Fabio Kolar y Ulrich Mücke, asume el desafío de analizar los conservadurismos y derechas en América Latina y la península Ibérica en el extenso período que abarca dos siglos, lo que implica estudiar procesos y actores muy diversos. Las dificultades del cometido están señaladas en la muy sugerente introducción que realizan los editores, quienes plantean que hasta las décadas finales del siglo XX las sociedades iberoamericanas eran consideradas comunidades atrasadas, estancadas en el pasado y ajenas a toda forma de revolución. Las transiciones democráticas y la renovación historiográfica que se produjo en torno a los cambios políticos, trajo una nueva perspectiva sobre los procesos históricos y se comenzó a atender la implantación del orden constitucional, los procesos electorales y la constitución de la ciudadanía. Hoy, existe un consenso en que las independencias 
introdujeron cambios políticos radicales e incluso revolucionarios. Sin embargo, se ha producido un desequilibrio entre los numerosos estudios acerca del liberalismo y los más escasos análisis sobre los conservadurismos y las derechas. Solo en las dos últimas décadas se empezó a consolidar un campo de estudios que aborde esos idearios y sus prácticas. Kolar y Mücke entienden que se trata de estudios todavía muy limitados a las fronteras nacionales. Si bien, en principio no deja de ser cierto, la afirmación debería matizarse, pues como se puede ver en el propio libro y en los encuentros, simposios y dossiers, cada vez son más los investigadores y las investigadoras que apuntan a trabajos comparativos y enfoques trasnacionales.

Por otro lado, los compiladores señalan las dificultades que generan la ambigüedad, el uso confuso y hasta arbitrario de los términos derecha y conservador. Como solución reclaman conceptos analíticos viables, que superen lo etimológico, las determinaciones clasistas y se enmarquen en su origen y en su propio contexto histórico. El término conservadurismo, tal como lo muestran los artículos del libro fue predominante en el siglo $\mathrm{XIX}$, en tanto que en el siglo $\mathrm{XX}$ se impuso el concepto derecha (condicionado relacionalmente con el término izquierda). La derecha se definirá por su contrariedad con las formas igualitaristas, ya que conciben que la desigualdad es natural e inmutable. Conservadurismos y derechas se relacionan en el respeto a las tradiciones. No obstante, reconocen que resulta muy difícil, sino imposible, formular una definición universal para todas las variantes históricas y geográficas. Los editores entienden que las nuevas derechas fueron y son herederas del pensamiento conservador del siglo XIX, pero al mismo tiempo son creaciones del siglo $\mathrm{XX}$, con sus propias características (pp. 7-36).

La estructura del libro podría dividirse en tres secciones, una primera parte que aborda los procesos del siglo XIX, una segunda que se desenvuelve en el rico período finisecular y finalmente, una tercera parte que recorre diferentes experiencias del siglo $\mathrm{XX}$.

El artículo de Lucia Maria Bastos Pereira das Neves, sobre los lenguajes políticos de las élites políticas y culturales en el período independentista del Imperio Brasilico, abre los análisis sobre el siglo XIX. La autora sostiene que conservadurismo es un concepto moderno, opuesto a los valores del Antiguo Régimen, que puede considerarse como una "tendencia política liberal", equidistante del progresismo tanto como absolutismo retrógrado. Su perspectiva analítica la lleva a detenerse en el estudio de algunos conceptos centrales, tales como soberanía, constitución y ciudadanía. El Imperio se expresaba como un gobierno inspirado en la soberanía de la nación y revestido por un lenguaje liberal moderado. Así, la Constitución de 1824 expresaba la voluntad de un gobierno conservador pero siempre constitucional, aunque las élites se habían despegado muy poco del campo de experiencia previa, la cultura política y pública continuaba siendo restringida y la esclavitud seguía sosteniendo la economía.

Por su parte, Víctor Peralta Ruiz examina la confluencia de realismo y conservadurismo en la independencia de Perú, advierte que convivían un liberalismo realista y el realismo absolutista. Discute así el tópico de la historiografía criolla que asociaba exclusivamente realismo con absolutismo. Para el autor, el pensamiento político antiliberal del realismo absolutista (1810-1823) fue un movimiento reactivo y reacio a los cambios que conmovieron a la monarquía hispánica durante la coyuntura liberal de las Cortes de Cádiz. En Perú, sostiene, más que un partido conservador 
existieron personalidades que "conservadoramente" abrazaron la defensa del absolutismo como garante de la alianza entre el Altar y el Trono.

La pluralidad e influencia del catolicismo en la política mexicana de largo plazo es el tema central del artículo de Marta Eugenia García Ugarte. Así, hasta los liberales radicales, los de la segunda reforma, eran católicos. La autora sostiene que el catolicismo impregnó incluso a los proyectos modernistas. Asimismo, el extremo radical del partido conservador, que optó por la monarquía y el antiguo orden, se suele identificar con la catolicidad y su tradición.

Cristóbal Aljovín de Losada dedica su estudio al análisis del pensamiento teológico político del franciscano Pedro Gual, referente ultramontano en Perú y bastión de la reacción católica antiliberal entre 1845 y 1890. El autor afirma que el conservadurismo alcanzó en Hispanoamérica una fuerte impronta religiosa y desde allí batalló con el Estado, al presentarse como elemento integrador de la sociedad. Desde esa perspectiva, de Losada puede indagar sobre los vínculos entre republicanismo y catolicismo.

Erika Pani aborda la relación entre conservadurismo y soberanía popular, evidencia cómo la volatilidad inherente a la política moderna se superpuso a una guerra, la Guerra de Reforma, que aglutinó en el bando antireformista a buena parte de los oficiales del ejército, el alto clero, los católicos militantes y el grupo político que había promovido y sostenido la dictadura santanista. El conservadurismo concebía que la Constitución era disolvente, inmoral y destructora de los valores sociales, religiosos e incluso en los hogares. Por ello era necesario tomar las armas contra la demagogia y el deterioro de la autoridad.

Con un texto que examina un período extenso y se adentra en el siglo XX (18401923), Eduardo González Calleja investiga la fuerte tradición conservadora en armas que se desarrolló en España y que ejerció un influjo duradero en las ideas y actitudes de amplios sectores sociales. Al mismo tiempo, sostiene que el desarrollo práctico del concepto de orden social esgrimido por sectores de derecha, marcó los límites del alcance transformador del ciclo revolucionario liberal. La extendida defensa del orden social, más allá del conservadurismo, justificaba la desigualdad y la explotación considerado como algo natural y sirvió de sustento a diferentes procesos, incluida la dictadura de Primo de Rivera que apeló al somaten como garante de la seguridad interna.

En el capítulo Conservatismo y catolicismo en Colombia (1880-1930), Ricardo Arias Trujillo estudia el conservadurismo colombiano y su dinámica relación con el liberalismo en el período finisecular. Los conservadores establecieron alianzas con el catolicismo que fortalecían a ambos grupos. Sin embargo, el largo dominio conservador hizo pasar desapercibida su heterogeneidad, su dinamismo, su historicidad y su capacidad de atracción de nuevos adherentes, incluso liberales desencantados y la presencia de conservadores escasamente reaccionarios.

Los últimos capítulos del libro se dedican al análisis de las derechas en el siglo XX y ponen en evidencia la renovación del campo de estudios como la continua ampliación de los temas de investigación. Así, Irene Flunser Pimentel se dedica a indagar la formación de una élite femenina conservadora en el Estado Novo de Salazar. Desde una perspectiva anti patriarcal clásica, observa el carácter subordinado de las mujeres al Estado Novo, que las consideraba pilar de la familia y base de la reconstrucción moral a través de su función de madre y educadora de sus hijos en el 
reducido ámbito de lo doméstico, donde el jefe siempre era el marido. No obstante, la propia autora señala, que de todos modos, se dio una movilización política femenina y la conformación de una elite de mujeres derechistas que se hizo oír.

El artículo de João Fábio Bertonha, desde una perspectiva comparativa y desde el pensamiento político, aborda una cuestión recurrente del campo de estudio de las derechas: aquella que reflexiona sobre el carácter fascista de las experiencias iberoamericanas. El autor considera que en los años '20 y '30 hubo un fascismo latinoamericano, aunque no alcanzó el poder y se formuló de manera diferente en cada país. Ello, no obstante, no le impide a Bertonha definir la presencia de un fascismo ibérico.

Ernesto Bohoslavsky, Magdalena Broquetas y Gabriela Gomes estudian a las juventudes conservadoras de Argentina, Chile y Uruguay que se opusieron a las transformaciones progresistas de la década. Enmarcados en la noción del anticomunismo provista por la guerra fría, los jóvenes derechistas de los tres países estaban dispuestos a combatir el avance de los movimientos de izquierda y para ello adoptaron distintas formas de organización y prácticas que tenían un particular acento restaurador de los valores sociales y culturales.

Por su parte, Margareth Power, referente en la investigación sobre mujeres y derechas, aporta una mirada transnacional al comparar las movilizaciones femeninas contra Goulart en Brasil y Allende en Chile. Una vez más, el anticomunismo hermanó diferentes expresiones nacionales que se distanciaron por el lugar que ocupaban el catolicismo y el liberalismo en las culturas políticas de ambos países.

Finalmente, el artículo de Riccardo Marchi analiza el recorrido de una élite política -universitaria- portuguesa que va del nacionalismo al liberal-conservadurismo en el contexto del fin del Estado Novo y la transición democrática. Esas transformaciones llevan a los jóvenes derechistas a un abandono progresivo del nacionalismo revolucionario y del autoritarismo para acercarse a posiciones de reformismo liberal y del conservadurismo vigente en otros países europeos.

El libro, como puede advertirse en los brevísimos resúmenes de los capítulos que lo compone, pone de manifiesto la fuerte influencia del conservadurismo y las ideas de derechas en América Latina desde el siglo XIX y a lo largo del siglo XX, tanto como las alianzas y contactos particulares que se fueron construyendo en el tiempo y en diferentes espacios geográficos y políticos. Al mismo tiempo, la compilación refleja el afianzamiento de un campo de estudios que, desde el desarrollo alcanzado, puede avanzar en perspectivas transnacionales, poner en discusión la potencia y la pluralidad de idearios liberales, conservadores y religiosos, y analizar actores que, hasta hace poco tiempo, no habían sido objeto de investigación, pero que lograron ganarse un espacio en movimientos e idearios que inicialmente eran refractarios a la participación política de mujeres y jóvenes.

Se trata de una publicación que brinda un panorama amplio sobre las derechas iberoamericanas y, a la vez, invita a repensar el estatus epistemológico de los estudios acerca de las derechas y los conservadurismos. 